\title{
Do you really care doctor?
}

'The secret of care of the patient is in caring for the patient."

\section{INTRODUCTION}

One of the authors was reading a book on Buddhism the other day (as you do!) which made the following assertion: '... doctors who really care for their patients have patients who respond better to their treatment ...'?2 This would have remained interesting but largely unimportant had it not coincided with a meeting between said author and a psychiatry lecturer about potential teaching for fifth-year medical students on the principles and role of primary care mental health management. We won't bore you with the details of the discussion, but a view that the two experienced clinicians wanted to pass on in the teaching session was that a doctor's most fundamental role in relation to psychological medicine was to care. The two doctors/teachers agreed this is an experience that is difficult to teach and to convey, but nonetheless recognised the concept of the doctor as an invaluable drug. ${ }^{3}$ Hence this essay to explore whether doctors do, should, or ought to care and does it matter anyway?

The authors of this essay decided to look up information on Google ${ }^{T M}$ to support or refute our views that caring for patients actually matters. The first search involved the phrase 'caring doctors'. We found two particularly pertinent articles from the BMJ from recent years. First, a survey in Australia was reported under the headline, 'Being a caring doctor may be bad for you', and suggested that caring may be useful for patients but produced unwanted sideeffects in the form of poor mental health for newly qualified doctors. ${ }^{4}$ Second, a personal view suggested that in contemporary primary care, personal lists and excessive over-reliance on a personalised doctor-patient relationship can have a detrimental effect on patient care. ${ }^{5}$ These two suggested that caring is unhelpful and potentially dangerous to our own health - an inauspicious start.

However, we wanted to know if being a caring doctor produces better outcomes, so the next phrase we used to search was 'doctors who care outcomes'. The main two papers from primary care provided interesting information, both indicating that nurses can produce just as good clinical outcomes as doctors in the primary care arena. ${ }^{6,7}$ So now the results suggested that nurses and doctors are interchangeable in primary care, further suggesting that the specific role of the doctor may not be as valuable as originally thought. However, it also suggested that those who traditionally bring care as part of their core disciplines can also achieve good clinical outcomes.

This left us with a further series of quandaries in that both professions look after patients, but it was a view implied in medical school that doctors manage patients, whereas nurses care for patients. We felt this subject deserved a further consideration, specifically for us within a university department of primary care which is heavily involved in teaching. It further raised the question of whether we should get medical students and trainee doctors to understand and value care as a concept.

\section{WHAT IS CARE?}

A Wikipedia search (as favoured by many a medical student in our experience) reveals 'care' as a noun and means a concern or responsibility or the career/subject of looking after people, whereas the verb means to be concerned about, have an interest in or to look after. Each of us as GPs would recognise the definitions, and clearly we do care professionally in that a definition of a GP is to provide first point of contact medical care for a defined patient population. However, this brings us back to our original premise that this is perhaps a dispassionate and narrow definition, and if this is the case how can GPs demonstrate care for their patients in an upright, decent, respectful, and holistic manner?

It is well known that the main 'equipment' that GPs strive to use is that of good communication skills, and that these have been demonstrated to produce better outcomes. ${ }^{8}$ Further, it has been noted before that GPs can act as paragons within their community, ${ }^{9}$ and that they have a priest-like role, which is aided by actually 'giving a damn'. ${ }^{10}$ Further, GPs still provide relevant triple diagnosis (the 'biopsychosocial model') and management including a listening ear, ${ }^{11}$ and this is extended into the realm of palliative care (where caring about patients as people is paramount) which should continue to be an important element of the GP role. ${ }^{12}$

So, how can GPs prove they care (should they choose to do so)? This has been exemplified in a marvellous personal paper in the BMJ about the role of doctor as friend as well as primary care provider. ${ }^{13}$ The paper exemplifies a paragon of oldfashioned values and decency fundamental to the job of being a GP, and we feel its core message deserves continuing attention. We consider the following may help to view some aspects of the job as demonstrating care: house calls viewed as a privilege rather than an annoyance, a telephone call to see how patients are fairing, a judicious offer of support at times of difficulty; all prove we care, to ourselves, our colleagues, and our patients.

\section{CUM SCIENTIA CARITAS}

It has been noted before that the motto of the RCGP is Cum Scientia Caritas (Science with Compassion); this has been discussed before in the context of evidence-based medicine. ${ }^{14}$ However, the central premise of this essay is on the role of Caritas, and how it can be discussed, portrayed, and valued. A further Wikipedia search on the meaning (or interpretation) of the Latin word Caritas indicates that at times it refers to compassion, at times it refers to caring, and at times it has a meaning akin to charity as a virtue. Each of these has pertinence for our present discussion, but clearly Caritas involves doctors being at the very least mindful and respectful of their patients.

It is a given that GPs and others in the medical profession should put the views of patients high in their list of priorities in this era of patient-centredness, notwithstanding the potential conflict 
posed by our contemporary target-driven culture. ${ }^{15}$ Furthermore, in future, for revalidation and continuing GMC registration purposes, GPs will have to be assessed by their colleagues and patients, in a manner akin to the present reaccreditation system, but in a more profound manner. ${ }^{16}$ The Scientia part of the RCGP motto is beyond the remit of this essay but the Caritas part will clearly apply in relation to patients.

So how do medical students learn about the values of the profession they join, and how do qualified doctors maintain this learning? The issue of how students learn about professionalism is of profound recent interest in medical education literature; $;^{9,17,18}$ essentially the literature suggests that a mixture of theoretical understanding, pragmatic experiential teaching, and reflection will help students most. This is helped by continual reflection on the core values of the profession, which is where the General Medical Council fits in for all doctors, and the Royal College of General Practitioners fits in for GPs.

In a particularly seminal and pertinent work, Donald Schon discussed how those who join a profession gradually learn its values; ${ }^{19}$ after they have learned the technical skills required to practise professionally, they undergo a period of reflective practice by thoughtfully considering professional encounters while being coached by professionals in the discipline. These lessons continue during individuals' professional careers, particularly relevant in this era of portfolio learning. It is surely to be hoped that future generations of doctors will continue to be taught and mentored by those who continue to uphold decent professional values, which we hope would include notions of care as exemplified by the definitions of Caritas mentioned before.

However, we note several issues which may make caring a complex issue both to contemplate and to 'teach'. First, a qualitative study of views of medicine held by 52 doctors in the UK suggests that doctors have difficulty assimilating notions of care into the technical aspects of their professional work. $^{20}$ Second, a questionnaire study of medical undergraduates in the US suggests that medical students lose what the authors term 'vicarious empathy' (a form of humane empathic caring) during their time at medical school. ${ }^{21}$ The authors conclude that empathy (equivalent to the verb definition of care described above) should be reinforced during student education because a loss of care is detrimental to the patient's need for an empathic caregiver. To paraphrase, we suggest that for optimum care-giving, doctors should be encouraged to allow themselves to care.

\section{WHEN DOCTORS DON'T CARE}

We are not inexhaustible resources, and cannot be expected to be able to provide perfect care for all patients all of the time, even in an ideal world, and many would argue that the 'worried well' take up too much of our precious time. We are well aware of the nature of general practice, and the Australian survey reported earlier should give us pause for thought. ${ }^{4}$ Further, the job/vocation involves such a level of intensity at times that it becomes more difficult to maintain our highest standards, even if this were appropriate to regard as a Platonic ideal.

However, this essay is more concerned with potential systematic 'processes', which can leave doctors consistently and persistently less empathic, less kind, and less caring. The first of these is burnout, ${ }^{22}$ which is a slowly developing insidious condition that may be difficult to spot or to 'manage'. As noted above, at times we may have (hopefully temporary) features of burnout. Any GP can experience times where we do not, or cannot, care what befalls our patients. However, we feel it should be of concern if a doctor continues to fail to respond to patient needs for Caritas, and that this may be indicative of burnout.

The second concern is that of heartsink. ${ }^{23}$ All GPs would recognise the illdefined quality of a patient who may be considered a personal heartsink, and we would all recognise that the first surgery on return from holidays will invariably contain more heartsinks on average. However, this should only be a temporary blip, and we should return to our normal quota in time. The notion of heartsink is invariably vague, but we contend that the notion is similar to that of burnout, in that too many heartsinks might be due to an absence of care.

This leaves us with the concept of what to do with those qualified doctors who have been demonstrated to care 'insufficiently'. The new GMC registration process is intended to discover those doctors who are performing poorly, and surely this will include those who have poor relationships with their patients; ${ }^{16}$ some patients may contend that these individual doctors do not appear to care. Hopefully, this essay will generate some thoughts as to how to help those qualified doctors who need to rekindle their (presumed) zeal for caring for patients as their highest professional goal.

\section{CONCLUSION}

It is an implicit tenet of this essay that in order to care, all GPs need support as people too. This support should come from government (who should recognise the inherent value of our role), colleagues (who recognise our positive qualities), staff (who can act as our support at work), patients (and it does when GPs recognise the gratitude shown by patients in their hour of need), and from our families (who should love us for all the right reasons). In turn, we should be grateful for having the privilege of doing a job that is pertinent and continues to be relevant.

Viewing the job as a privilege is a difficult notion and slightly contentious, but in principle it is an echo of the concept of doing the right thing for the right reasons, and for the inferred benefit that will accrue to us as individuals. As such, we contend that this sounds plain silly if we were to overtly teach this, but it is a concept that is worthy of sharing with medical students as they prepare for their professional careers, and with those qualified doctors who may require retraining. Therefore, we recognise that this is a subject which can be 
broached to individual learners, but that it is only through experience that this will reach fruition.

We can lead by example by being good role models ${ }^{9,24}$ and by recognising that care, although vague and nebulous, is a necessary part of our role. We note there is a parallel that, just as good doctors should care about patients, so good teachers should care about students. However, the outcomes of such a strategy may be difficult to measure. Therefore, many would regard this essay as naïve and unhelpful, but we contend that care is not an abstract concept but is necessary to both make us into good doctors, and to keep us as good doctors. As a summation of our thoughts we would continue the Hippocratic concept of 'first do no harm' to include the dictum '... and if possible do some good by demonstrating you care'.

\section{Lionel Jacobson, Anne Marie Cunningham, Giles Greene, Lucy Morris and Emma Melbourne}

\section{REFERENCES}

1. Peabody F. The care of the patient. JAMA 1927; 88(12): 877.

2. Causton R. The Buddha in daily life: an introduction to the Buddhism of Nichiren Daishonin. London: Rider Press, 1995: 107.

3. Balint M. The doctor, his patient and the illness. London: Pitman Medical Press, 1957.

4. Sweet M. Being a caring doctor may be bad for you BMJ 2003; 326(7385): 355.

5. Mackenzie $\mathrm{G}$. The caring doctor is an oxymoron. $B M J$ 1997; 315(7109): 687-688.

6. Mundinger M, Kane R, Lenz E, et al. Primary care outcomes in patients treated by nurse practitioners or physicians. JAMA 2000; 283(1): 59-68.

7. Laurant M, Reeves D, Hermens R, et al. Substitution of doctors by nurses in primary care. Cochrane Database Systematic Rev 2005; 2: CD001271.

8. Kurtz S, Silverman J, Draper J. Teaching and learning communication skills in medicine. Abingdon: Radcliffe Medical Press, 1998.

9. Jacobson L, Hawthorne K, Wood F. The 'Mensch' facto in general practice: a role to demonstrate professionalism to students. Br J Gen Pract 2006 56(533): 976-979.

10. Pink J, Jacobson L, and Pritchard M. The 21st century GP: physician and priest? Br J Gen Pract 2007; 57(543): 840-842.

11. McWhinney I. A textbook of family medicine. Oxford: Oxford University Press, 1996.

12. O'Neill B, Fallon M. ABC of palliative care: principles of palliative care and pain control. BMJ 1997; 315(7111): 801-804.

13. Loxtercamp D. A friend in need: why friendship matters in medicine. BMJ 2008; 337: a528.

14. Jacobson L, Edwards A, Granier S, Butler C. Evidencebased medicine and general practice. Br J Gen Pract 1997; 47(420): 449-452.

15. Mangin D, Toop L. The Quality and Outcomes Framework: what have you done to yourselves? $\mathrm{Br} J \mathrm{Gen}$ Pract 2007; 57(539): 435-437.

16. General Medical Council. Licensing and revalidation. http://www.gmc-uk.org/about/reform/index.asp (accessed 4 May 2009).

17. Spencer J. Teaching about professionalism. Med Educ 2003; 37(4): 288-289.

18. Hilton S. Medical professionalism: how can we encourage it in our students? Clin Teach 2004; 1(2): 69-73.

19. Schon D. The reflective practitioner: how professionals think in action. London: Temple Smith, 1983.

20. Nettleton S, Burrows R, Watt I. How do you feel doctor? An analysis of emotional aspects of routine professiona medical work. Social Theory and Health 2008; 6(1): $18-36$.

21. Newton B, Barber L, Clardy J, et al. Is there hardening of the heart during medical school? Acad Med 2008; 83(3): 244-249.

22. McManus I, Winder D, Gordon B. The causal links between stress and burnout in a longitudinal study of UK doctors. Lancet 2002; 359(9323): 2089-2090.

23. McDonald P, O'Dowd T. The heartsink patient: a preliminary study. Fam Pract 1991; 8: 112-116.

24. Cruess S, Cruess R, Steinert Y. Role modelling making the most of a powerful teaching strategy. BMJ 2008; 336(7646): 718-721.

DOI: 10.3399/bjgp09X453378 